\title{
Developing Brief Opportunistic Interactions: practitioners facilitate patients to identify and change health risk behaviours at an early preventive stage
}

\author{
Barbara Docherty ${ }^{1,2}$, Nicolette Sheridan ${ }^{3,4}$ and Timothy Kenealy ${ }^{5}$ \\ ${ }^{1} \mathrm{RN}$ (Registered Nurse) \\ ${ }^{2}$ Honorary Clinical Lecturer, School of Nursing, Faculty of Medical and Health Sciences, University of Auckland, \\ Auckland, New Zealand \\ ${ }^{3}$ Faculty of Medical and Health Sciences, University of Auckland, New Zealand \\ ${ }^{4}$ Associate Dean Equity, Faculty of Medical and Health Sciences, University of Auckland, Auckland, New Zealand \\ ${ }^{5}$ Associate Professor of Integrated Care, University of Auckland, Auckland, New Zealand
}

\begin{abstract}
Aim: To identify shortcomings in existing models of patient behaviour change, and present the development and testing of a novel approach using practitioner facilitation and person-focussed conversations that identifies and addresses behaviours at an earlier stage than current models. Background: Systematic strategies used by health professionals to change patient behaviours began with motivational interviewing and brief intervention approaches for serious addictive behaviours. Practitioners typically presume they should drive the process of patient behaviour change. Attempts to transfer these approaches to primary care, and a broader range of health risk behaviours, have been less successful. The TADS programme (Tobacco, Alcohol and Other Drugs, later Training and Development Services) began teaching motivational interviewing and brief interventions to practitioners in New Zealand in 1996. Formal and informal evaluations showed that practitioners used screening tools that patients rejected and that led to incomplete disclosure, used language that did not engage patients, failed to identify the behaviours patients wished to address and therefore misdirected interventions. Methods: Iterative development of new tools with input from patients and primary care clinicians. Findings: The TADS programme developed a questionnaire whose results remained private to the patient, which enabled the patient to identify personal behaviours that they might choose to change (the TADS Personal Assessment Choice Tool). This was assisted by a brief conversation that facilitated and supported any change prioritised by the patient (the TADS Brief Opportunistic Interaction). The need for this approach, and its effectiveness, appeared to be similar across adults, youth, different ethnic groups and people in different socio-economic circumstances. Behaviours patients identified were often linked to other health risk behaviours or early-stage mental health disorders that were not easily detected by practitioner-driven screening or inquiry. The long-term effectiveness of this approach in different populations in primary health care settings requires further evaluation.
\end{abstract}

Key words: behaviour change; brief interventions; doctor-patient communication; motivational interviewing; nurse-patient communication; primary health care

Received 6 January 2015; revised 6 July 2015; accepted 13 October 2015;

first published online 20 November 2015

Correspondence to: Barbara Docherty, Unit 1, 67 Vauxhall Rd, Devonport, Auckland 0624, New Zealand. Email: barbara.docherty@ clear.net.nz

(C) Cambridge University Press 2015. This is an Open Access article, distributed under the terms of the Creative Commons Attribution licence (http://creativecommons.org/licenses/by/4.0/), which permits unrestricted re-use, distribution, and reproduction in any medium, provided the original work is properly cited. 


\section{Introduction}

Nearly half of premature deaths from the 10 leading causes of mortality worldwide are attributable to personal behaviours (Lopez et al., 2006; Alwan et al., 2011). Collectively, they account for almost threequarters of all medical care spending (Gruman and Follick, 1998). Half of all mental health disorders in adulthood start by age 14, but most cases are undetected and untreated (World Health Organization (WHO), 2014). Young adults are emerging as a new and neglected priority in global health (Horton, 2012). In 2012, an estimated 1.3 million adolescents died mostly from preventable or treatable causes. Health risk behaviours related to alcohol or tobacco use, lack of physical activity, unprotected sex and/or exposure to violence can impact both current and future health (WHO, 2014).

Primary health care and general practice settings are frequently proposed as the ideal environment for opportunistic and systematic behavioural change interactions. In New Zealand about $80 \%$ of the population visit a general practitioner (GP) and about $40 \%$ visit a primary health care nurse every year (Ministry of Health, 2008).

There are widespread attempts to address population health by identifying individual health risk factors and risky behaviours. Payment systems and policy mandates require, for example, collection of data to meet Quality and Outcomes Framework criteria in the United Kingdom (NHS Information Centre, 2012), or a targeted percentage of adults having cardiovascular risk assessments in New Zealand (Ministry of Health, 2015). Nurses in chronic care management clinics often follow a consultation structure based on the nurse determining what behaviours the patient needs to change (Jansink et al., 2010). There is an (often unspoken) assumption that if practitioners collect data which shows risks, they will act on this data and this action will change patient behaviour and risks. What happens too often is assessment without intervention (Parsons et al., 2013) or intervention with disappointingly small effect (Kenealy et al., 2011).

Practitioners are often under-prepared to discuss health risk behaviours with patients (Chisholm et al., 2012). Many practitioners claim lack of time as the main barrier to their changing patient behaviour (Kenealy et al., 2010; Finlayson et al., 2012) rather than recognising barriers internal to themselves (Ogden et al., 2004). Many practitioners resort to unsolicited advice, despite evidence that this can be unwelcome and that health is often insufficient motivation for change (Rollnick et al., 1993; Emmons and Rollnick, 2001). Dart suggests 'we become emotionally invested in our patients ... [and] believe we know what is best for them' (2011). Welch et al. (2006) contend that feeling responsible for fixing 'broken' patients reinforces the propensity of doctors and nurses to do most of the talking, supported by a belief that patients can change 'if they really want to' (McCabe, 2004). This is a short step to making moral judgements about 'bad' patients (Hill, 2010).

Nurses can make assumptions about their patient's needs (Docherty, 2013) and their own lifestyle practices may influence any willingness to change patient behaviours. Clinicians who smoke are less likely to raise the issue of smoking with patients (Frank, 2004), and many fear that this will lead to conflict with their patients (Sim et al., 2009). Behaviours discussed are often highly selected and poorly prioritised to the needs of the individual patient. Tobacco smoking, obesity and physical activity are frequently identified in isolation from other high-risk activities, such as gambling, that may be associated with depression and hazardous alcohol use (Goodyear-Smith et al., 2006). Tobacco smoking interventions are much more likely to be discussed in primary health care settings than cannabis, despite three cannabis joints causing as much harm as 20 cigarettes (Aldington et al., 2008). Young people admitted to hospital for diabetes have an increased risk of suicide (Roberts et al., 2004), yet mental health is not a routine part of general practice diabetes care.

Health professionals have long attempted to change patient behaviour without the application of a strong theoretical basis and related training. Smith et al. (2006) suggest communication is about informing, influencing and motivating individuals. Elder et al. (1999) refer to informational power and expert power being used to convince patients to change using unsolicited advice while linking any non-conformity to possible severe health outcomes.

Motivational interviewing (MI) is an approach to behavioural counselling that seeks to 'elicit and strengthen motivation for change' (Miller, 1983). It was first applied to alcohol and later to heroin addictions (Miller, 1983) and is considered by 
some to be the most effective theoretically based intervention. It has been defined as 'a directive, client-centered counselling style for eliciting behaviour change' (Rollnick and Miller, 1995; Miller and Rollnick, 2009). MI continues to form the basis of behavioural change approaches to treatment (Coulter and Collins, 2011). The Transtheoretical Model of behaviour change was a logical extension of MI developed by Prochaska and DiClemente as a means to understand the process of addiction recovery (Prochaska and DiClemente, 1983; Prochaska et al., 1992). Other behavioural change variations, mostly based on MI, have been loosely and collectively labelled as brief interventions (BIs), despite a number of differences in the delivery mechanisms and settings in which they were developed. Recent New Zealand BI programmes introduced into primary care include ABC (Ask, Brief Advice, Cessation Support) for smoking cessation (Ministry of Health, 2007) and ABC (Ask, Brief Advice and Counselling) for reducing alcohol consumption (Royal New Zealand College of General Practitioners, 2012). Cognitive Behavioural Therapy (CBT) is a psychotherapeutic approach that aims to alter attitudes and behaviours by replacing inaccurate thoughts (New Zealand Guidelines Group, 2012). Delivering a full CBT programme is beyond the scope of most primary care practitioners. The Flinders Program $^{\mathrm{TM}}$ (Lawn et al., 2009) is a semi-structured programme for disease-specific management based on both CBT and MI principles.

Effectiveness of behavioural change interventions can be seen at individual, community and population levels (Michie and West, 2013), although effects tend to be modest, with significant heterogeneity of effects over both short and long terms (Michie et al., 2008). Evaluations of effectiveness have been hindered by the absence of a gold standard for measuring health behaviours (Vitolins et al., 2000). Few behavioural change approaches have been tested in real-world longitudinal studies and some trials have been criticised for being clinically unrepresentative (Kaner et al., 2007). Nil to modest effects have been shown on alcohol consumption (Wutzke et al., 2002), physical activity (Smith et al., 2002), eating habits (Dunn et al., 2001), substance abuse, high-risk adolescent behaviours and a variety of chronic diseases (Wagner et al., 2000; Sammut, 2009).

\section{Developing Brief Opportunistic Interactions (BOls)}

The BOI approach was developed from the Tobacco, Alcohol and other Drugs Early Intervention Project (TADS) at the University of Auckland, New Zealand, following involvement in the WHO Collaborative Project on Identification and Treatment of Persons with Harmful Alcohol Consumption in 1996 (Heather, 2006). The WHO project sought to develop a scientific basis for screening and BIs in primary care settings and to examine ways of engaging general practices in implementing a BIs approach (McCormick et al., 1999). Author B. D. was the TADS Project Manager from 1998 to 2006. The full name of TADS was changed in 2006, to Training and Development Services to reflect the move beyond a focus on tobacco and alcohol.

Starting in 1998, the TADS BIs training was implemented in many areas of New Zealand funded by the New Zealand Ministry of Health. A concurrent programme of evaluation drew on existing literature and used formal and informal qualitative and action research methods. There was constant critical reflection while continuously refining methods and ideas (Whitehead et al., 2003). Notes were taken but conversations were not recorded. Data were collected over 10 years from practitioner workshop participants (6500), consumer feedback (2500 adults and 348 youth), facilitator observation and feedback, and observation in real-world situations (Nemec, 2001). Practitioners came from general practice, school clinics and other primary health care settings. Consumers included people of European, Māori and Pacific ethnicities.

The programme that developed included three key elements: a new language for practitionerpatient interactions, a focus on opportunistic prevention that was not limited to alcohol and tobacco, and a process that enforced patient priority in identifying issues to be addressed. Central to the process is the Personal Assessment Choice Tool $\left(\mathrm{PACT}^{\circledR}\right)$, a questionnaire which comes in two versions, adult and adolescent (see Appendices). The way it is used is described in the next section. The unique feature is that $\mathrm{PACT}^{\odot}$ responses are not viewed at any stage by practitioners. Questions relate to use of tobacco, alcohol, other drugs, gambling, mild to moderate mental 
Table 1 Examples of BOI language

\begin{tabular}{|c|c|}
\hline Practitioner driven & Person focussed (BOI) \\
\hline $\begin{array}{l}\text { 'You have diabetes and will have to make some behavioural } \\
\text { changes' }\end{array}$ & $\begin{array}{l}\text { 'Tell me what you already know about diabetes and } \\
\text { what that means for you' }\end{array}$ \\
\hline 'How many times a week are you going to the gym?' & $\begin{array}{l}\text { 'What are the things you enjoy most about going to the } \\
\text { gym?' }\end{array}$ \\
\hline $\begin{array}{l}\text { 'It's really important that you take your medication if you don't } \\
\text { want another heart attack ...' }\end{array}$ & 'What do you dislike most about taking medication?' \\
\hline $\begin{array}{l}\text { 'Tell me about these problems' ‘How much weight have you } \\
\text { lost?' }\end{array}$ & $\begin{array}{l}\text { 'What have you noticed most since changing the way } \\
\text { you are eating?' }\end{array}$ \\
\hline 'It's often a good idea not to take life too seriously' & 'What is the main thing that triggers your sadness?' \\
\hline 'How many cigarettes do you smoke each day?' & $\begin{array}{l}\text { 'What do you enjoy about smoking? And what's not so } \\
\text { great?' }\end{array}$ \\
\hline Let's talk about all these problems & $\begin{array}{l}\text { 'If you could change one thing in your life at the } \\
\text { moment what would that be?' }\end{array}$ \\
\hline
\end{tabular}

$\mathrm{BOI}=$ Brief Opportunistic Interaction.

health risks (anxiety and feeling down), anger, violence, physical activity and weight issues. Sexual health is included in the youth version.

The need for a new language was identified by both practitioners and consumers. Pre-training assessments identified that GPs and practice nurses were uncertain how best to approach behavioural change, had lengthy conversations despite feeling time-poor and felt frustrated at poor outcomes (Docherty, 2001). Surveys of adults and young people identified health professionals' attitudes and behaviour (such as preaching, advice and judgement) as barriers to personal behaviour change. This was consistent with literature suggesting that practitioner word choice could negatively influence patient decisions (Freeman and Sweeney, 2001), and that practitioners could actively avoid or block communication, such as by denial of patients' concerns, abruptly changing the subject or focussing on the least threatening aspect of a conversation (Webster, 1981; Booth et al., 1999). Examples of BOI language are given in Table 1.

The need for a programme much wider than just tobacco and alcohol was also identified by both practitioners and consumers (Docherty, 2001). Early findings from the TADS programme were that many young people and adults had multiple personal behavioural practices which interlinked. Mild to moderate mental health issues were mostly linked to a current personal behavioural practice such as alcohol, other drugs or gambling rather than a mental illness requiring specialist referral or medication. This led to a broad, opportunistic, preventative approach that allowed all behaviours and mental health risks to be addressed.

It became clear that practitioners did not, perhaps could not, correctly identify patient priority issues. A total of 82 practitioners were shown 339 anonymous PACT ${ }^{\circledR}$ responses, together with the socio-economic status and age of each patient, then asked which behaviours they would choose to start the change process with each patient. The behaviours chosen by health practitioners were not those chosen as the priority starting point by $98 \%$ of Adult $\mathrm{PACT}^{\odot}$ patients and $96 \%$ of Youth PACT ${ }^{\odot}$ patients.

That $\mathrm{PACT}^{\odot}$ responses remain private was a strong desire of the participants who helped develop the programme (Parsonage, 2006; TADS Training Programme, 2006). Participants feared judgement by health professionals particularly for behaviours that are illegal, stigmatised or invite moralising (Brener et al., 2003). Privacy protects trust in preparation for the second stage of the BOI process where individuals choose their own starting point of change from their PACT ${ }^{\odot}$ responses. The $\mathrm{PACT}^{\odot}$ questionnaire provides an opportunity for each person to privately gain a snapshot of their current behaviours and mental health risks. Both adult and adolescent participants were clear that they did not want to address any issues immediately as they would feel overwhelmed. They valued the opportunity to think more about any identified behaviours and preferred to use the next opportunistic visit to discuss them. 
Table 2 Questions at the second visit

What do you currently enjoy about the behaviour you have chosen?

What do you not like about it?

How important is it to you to change that behaviour? Scale of $1-10$

How confident do you feel that you can change this behaviour? Scale of 1-10

What could be getting in the way of changing this behaviour?

How do you feel about making a plan together next time you come?

The final version of the Youth PACT ${ }^{\odot}$ was tested opportunistically by nurses with 132 students aged 13-14 years across a full range of schools by socio-economic groups, and a wide range of ethnicities, in four geographical areas of New Zealand. They found similar behavioural and mental health risk responses across all school socio-economic groups and student ethnicities. The final version of the Adult PACT ${ }^{\odot}$ was tested opportunistically in general practice and other settings over four years. Testing covered 216 participants of all ethnicities and a wide range of occupations. The TADS PACT ${ }^{\odot}$ was acceptable and non-threatening to both adult and youth, across diverse populations by age, ethnicity and income (TADS Training Programme, 2007; Spoth et al., 2008) and in diverse clinical settings (Carroll et al., 2007). GPs said their understanding of person-focussed behavioural change approach improved markedly and their sense of patient engagement in the consultation improved when they changed to BOI language. Practice nurses valued the 'generic' conversation capability they could use in all types of consultations, particularly around diabetes and other chronic conditions.

Implementation of this approach through New Zealand primary health care has been constant but slow and partial. Surveys and feedback from course 'graduates' point to practice systems and contractual funding arrangements as the main impediments to implementing BOI in general practice. Nurses stated that implementation fidelity was difficult to achieve if others in their workplace were not also trained in the BOI approach, resulting in feelings of isolation, loss of confidence and lack of support. Nurses, in particular, have consistently recommended TADS training as a core requirement for professional development and said it was significantly more relevant than the many disease-specific and repetitive short courses on offer.

\section{The BOI approach and the $\mathrm{PACT}^{\odot}$ in practice}

The process unfolds over at least three visits. The first and second are opportunistic when the patient attends for something else. The third is organised for the purpose of making a behaviour change plan. Further short BOI conversations can continue whenever the patient presents to ensure ongoing self-management support. The first stage starts with the $\mathrm{PACT}^{\odot}$ questionnaire, which can be offered to those over 14 years of age in any face-to-face setting where behavioural change discussions occur. The $\mathrm{PACT}^{\odot}$ responses are stored securely and not viewed by practitioners.

The second stage happens at the next opportunistic encounter when the practitioner reminds the patient about the PACT ${ }^{\circ}$ and asks if they can identify a priority issue or behaviour they may want to address. This is followed by six questions, which help define whether the person is able, ready and willing to make changes (Table 2). The practitioner is trained to suspend the usual practice of 'needing to know' or 'diagnosing' the 'problem'. Using non-directive language, the practitioner facilitates the patient through their own decisionmaking process relating to the behaviour or mental health risk the person has chosen to address, at the same time helping to remove any obstacles to change. More details will emerge and be disclosed as the patient so chooses. At a later visit, the practitioner works with the patient to develop a plan, at which stage the process is similar to other approaches to self-management.

BOI language is more conversational than usual consultation styles we have observed. As it is inherently person focussed, for example, starting a conversation by asking 'What do you already know about ...?', it has been used successfully within research interviews in three New Zealand projects: the Diabetes Tracking Study (Dowell et al., 2010), the Very High Intensive Users (Rea et al., 2010) and assisting immunisation co-ordinators to engage with their stakeholders (Docherty, 2006). 
The Youth $\mathrm{PACT}^{\odot}$ contains simple, short, straightforward questions relating to tobacco, alcohol, other drugs, physical activity, weight, gambling, stress, anxiety, anger, sexual activity, feeling different to mates

\section{Joshua's story}

Joshua was referred by a teacher to the school nurse 'to discuss his weight problems'. After three visits both Joshua and the nurse reported no progress The nurse offered Joshua the opportunity to complete the Youth PACT ${ }^{\odot}$ rather than discuss his weight. She explained that the PACT ${ }^{\odot}$ would give him his own personal snapshot picture as to what might be going on in his life and that neither she nor anyone else would ever see the answers. No behavioural change discussion took place at that visit in order for his responses to slowly assimilate without practitioner persuasion and perhaps 'sow a seed'. The nurse utilised BOI language to facilitate in this and all subsequent interactions with Joshua

\section{The process and dialogue}

Stage 1. Joshua completed the Youth $\mathrm{PACT}^{\odot}$, which he signed, sealed and dated before it was locked away in a special cabinet

Stage 2. At his next visit Joshua opened the $\mathrm{PACT}^{\odot}$ when offered by the nurse

Nurse: 'If you could choose one thing from your answers on the $\mathrm{PACT}^{\odot}$ - something that you don't want in your life anymore - which would be number one?'

Joshua replied he had 'ticked a lot of things' then identified the question 'Do you often feel that you are different to your mates and don't fit in?'

$\bigcup_{\mathrm{U}}$ Avoiding the usual lengthy 'why, what, how' questions the nurse asked 'What is the one thing that makes you feel different to your mates?'

J Joshua: 'Something I don't want to say Miss because you'll tell me I'm silly and stuff...'

Nurse: 'Does the thing you don't want to tell me about have anything to do with anything else you have ticked on the $\mathrm{PACT}^{\odot}$ ?'

Joshua chose 'Have you ever wanted to bet more and more on lotto, card games or the internet?'

Short BOI questioning followed to ascertain Josh's readiness, willingness and ability to start to think about making some changes to his gambling. It transpired that he played poker in the school grounds but felt different to his mates because they had more money to bet with than he did and he didn't want to lose their friendship. Using his parents' credit card for internet gambling at night he became more and more in debt and stayed up long hours. His mood swings - jovial when winning, down when losing - were attributed by teachers to 'hangovers'. The school counsellor was counselling him for alcohol misuse (he was a non-drinker). Joshua stated 'Everyone thinks I drink just because my dad does ... but I don't'. No one accepted this at the school and no one had considered a gambling problem

Outcome. Joshua and his family agreed to family counselling about the gambling, which later also included discussions about healthy eating as a family affair. The nurse reported a change in her practice after observing what occurred with Joshua and his response when she used BOI language. She noted that the weight issues were less important to Joshua than feeling different to his mates and the weight discussion eventually followed anyway. Joshua had chosen to return to the nurse of his own volition a few days after completing the $\mathrm{PACT}^{\odot}-$ a rare occurrence for behavioural change discussions with young people

Later when the nurse asked him what he thought of the PACT ${ }^{\odot}$ and the talks they'd had, he said: 'Awesome, easy as Miss ... you didn't tell me what to do. If it (the gambling) had gone on for much longer I probably would have topped myself' Nurse: 'How do you feel about that now Josh?'

Joshua: 'I'm ok now, cos I know what the problem is ...'

A suicide may have been averted

BOI = Brief Opportunistic Interaction; TADS = Tobacco, Alcohol and Other Drugs Services; PACT = Personal Assessment Choice Tool. Joshua (not his real name) was 14 at the time. 
Table 4 Summary of the three day BOI training programme

Day One: Current knowledge and learning defined

Pre-Workshop Assessments help identify gaps in participant knowledge and practice. Discuss current approaches/ resources/screening tools that participants use to assist patients in behaviour change, what works and what does not work for them. The $\mathrm{PACT}^{\odot}$ and $\mathrm{BOI}$ introduced. Process explained and practised including communication and engagement skills/reframing current conversations, getting to the priority need as chosen by the individual, the important role of personal behavioural practices and the links with mild to moderate mental health risks

Day Two: Learning a new approach

$\mathrm{BOI}$ fundamentals and concepts in depth and compared with $\mathrm{MI}$ and $\mathrm{BI}$ in primary care. How to define and determine readiness, willingness and ability of the person to make any changes to their identified behaviour/or mental health risk by using a series of short questions, which are followed in a correct sequence. These are based on the reasons why being just 'ready' is not enough to change behaviour for most people because they have to first believe that their current behaviour is 'bad' for them (bears little relationship to being 'healthy'); they will be better off if they change (personal level, financial, different to their mates); and they will have a good chance of succeeding if they try to change (need to know it will fit in with their current way of life). Practical applications and role plays continue throughout the training

Day Three: Cementing the new BOI skills

Competency-based skills using $\mathrm{PACT}^{\odot}$ and $\mathrm{BO}$ communication skills are practiced and demonstrated. All participants critique each other by changing roles as patient, practitioner and observer and assist each other with any roadblocks

$\mathrm{BOI}=$ Brief Opportunistic Interaction; $\mathrm{PACT}=$ Personal Assessment Choice Tool; $\mathrm{MI}=$ motivational interviewing; $\mathrm{BI}=$ brief intervention.

Table 3 illustrates BOI in action with a case study. The process in this case is typical, even though the outcome in question is extreme (though not unique). Table 4 summarises the BOI training programme.

\section{Practice implications and future research}

The BOI approach is an opportunistic, time efficient, low cost, preventative, generic approach to facilitate patients in identifying existing or emerging personal behavioural practices, so as to actively choose their beginning, ongoing and end point of behaviour change.

The TADS research and development programme has identified what may be key ingredients missing from other behavioural change approaches. Formal evaluation to assess the TADS programme's contribution to performance of health practitioners and health outcomes for patients is now required.

Requests for the PACT ${ }^{\odot}$ to be made available online have been rejected by TADS on the basis that this could allow untrained practitioners to use the tool but continue with their practitioner-driven approach to behaviour change. The PACT ${ }^{\circledR}$ was conceived, developed, refined by patients who entrusted it to use following a competency-based training programme that supports practitioners. Enquiries about use of the tool and appropriate training should be directed to the first author.

\section{Acknowledgement}

The authors wish to acknowledge the large number of consumers who influenced the redevelopment of the TADS programme.

\section{Financial Support}

We received no funding specific to this work.

\section{Conflicts of Interest}

B. D. was paid as Project Manager to deliver and manage the workshops, which led to developing the current TADS programme. During this time she was employed by the University of Auckland through a contract funded by the Ministry of Health. N. S. and T. K. have no conflicts of interest.

\section{Ethical Standards}

No ethics approval was sought or required to develop the TADS programme. 


\section{References}

Aldington, S., Harwood, M., Cox, B., Weatherall, M., Beckert, L., Hansell, A., Pritchard, A., Robinson, G. and Beasley, R. 2008: Cannabis use and risk of lung cancer: a case-control study. European Respiratory Journal 31, 280-86.

Alwan, A.D., Galea, G. and Stuckler, D. 2011: Development at risk: addressing noncommunicable diseases at the United Nations high-level meeting. Bulletin of the World Health Organization 89, 546.

Booth, K., Maguire, P. and Hillier, V.F. 1999: Measurement of communication skills in cancer care: myth or reality? Journal of Advanced Nursing 30, 1073-79.

Brener, N.D., Billy, J.O. and Grady, W.R. 2003: Assessment of factors affecting the validity of self-reported health-risk behavior among adolescents: evidence from the scientific literature. Journal of Adolescent Health 33, 436-57.

Carroll, C., Patterson, M., Wood, S., Booth, A., Rick, J. and Balain, S. 2007: A conceptual framework for implementation fidelity. Implementation Science 2, 40-49.

Chisholm, A., Hart, J., Lam, V. and Peters, S. 2012: Current challenges of behavior change talk for medical professionals and trainees. Patient Education and Counseling 87, 389-94.

Coulter, A. and Collins, A. 2011: Making shared decisionmaking a reality. No decision about me, without me. London: Kings Fund.

Dart, M. 2011: Motivational interviewing in nursing practice: empowering the patient. Massachusetts: Jones and Bartlett.

Docherty, B. 2001: TADS evaluations of health professional needs for behavioural interventions. A survey and evaluation. Auckland, New Zealand: Goodfellow Unit, Department of General Practice, University of Auckland.

Docherty, B. 2006: Advocating immunisation. Are we needling people?, Lecture edition. Auckland, New Zealand: University of Auckland.

Docherty, B. 2013: Have current behaviour change approaches run their course? Get Connected: NZ Rural GP Network Conference, Rotorua, New Zealand.

Dowell, A.C., Stubbe, M., Kenealy, T., Sheridan, N.F., Dew, K. and Macdonald, L.M. 2010: Diabetes tracking study: understanding diabetes management: tracking communication in primary care. Wellington, New Zealand: University of Otago, Wellington School of Medicine.

Dunn, C., Deroo, L. and Rivara, F.P. 2001: The use of brief interventions adapted from motivational interviewing across behavioral domains: a systematic review. Addiction 96, 1725-42.

Elder, J.P., Ayala, G.X. and Harris, S. 1999: Theories and intervention approaches to health-behavior change in primary care. American Journal of Preventive Medicine 17, 275-84.

Emmons, K.M. and Rollnick, S. 2001: Motivational interviewing in health care settings. Opportunities and limitations. American Journal of Preventive Medicine 20, 68-74.

Primary Health Care Research \& Development 2016; 17: 319-332
Finlayson, M.P., Sheridan, N.F., Cumming, J.M. and Fowler, S. 2012: The impact of funding changes on the implementation of primary health care policy. Primary Health Care Research \& Development $13,120-29$.

Frank, E. 2004: Physician health and patient care. JAMA 291, 637.

Freeman, A.C. and Sweeney, K. 2001: Why general practitioners do not implement evidence: qualitative study. BMJ 323, 1100-2.

Goodyear-Smith, F., Arroll, B., Kerse, N., Sullivan, S., Coupe, N., Tse, S., Shepherd, R., Rossen, F. and Perese, L. 2006: Primary care patients reporting concerns about their gambling frequently have other co-occurring lifestyle and mental health issues. BMC Family Practice 7, 1-6.

Gruman, J. and Follick, M. 1998: Putting evidence into practice. The OBSSR Report of the Working Group on the Integration of Effective Behavioral Treatments into Clinical Care. Bethesda, MD, USA: Office of Behavioral and Social Sciences Research, National Institutes of Health.

Heather, N. 2006: Report on Phase IV. Development of country-wide strategies for implementing early identification and brief intervention in primary health care. WHO Collaborative Report on Identification and Management of Alcohol-Related Problems in Primary Health Care. Geneva: World Health Organization.

Hill, T.E. 2010: How clinicians make (or avoid) moral judgments of patients: implications of the evidence for relationships and research. Philosophy, Ethics, and Humanities in Medicine 5, 11.

Horton, R. 2012: GBD 2010: understanding disease, injury, and risk. Lancet 380, 2053-54.

Jansink, R., Braspenning, J., van der Weijden, T., Elwyn, G. and Grol, R. 2010: Primary care nurses struggle with lifestyle counseling in diabetes care: a qualitative analysis. $B M C$ Family Practice 11, 41.

Kaner, E.F., Beyer, F., Dickinson, H.O., Pienaar, E., Campbell, F., Schlesinger, C., Heather, N., Saunders, J. and Burnand, B. 2007: Effectiveness of brief alcohol interventions in primary care populations. Cochrane Database of Systematic Reviews $18(2)$.

Kenealy, T., Docherty, B., Sheridan, N. and Gao, R. 2010: Seeing patients first: creating an opportunity for practice nurse care? Journal of Primary Health Care 2, 136-41.

Kenealy, T., Orr-Walker, B., Cutfield, R., Robinson, E. and Buetow, S. 2011: Does a diabetes annual review make a difference? Diabetic Medicine 29, e217-22.

Lawn, S., Battersby, M., Harvey, P., Pols, R. and Ackland, A. 2009: A behavioural therapy approach to self-management: the Flinders Program. Diabetes Voice 54, 30-32.

Lopez, A.D., Mathers, C.D., Ezzati, M., Jamison, D.T. and Murray, C.J. 2006: Global and regional burden of disease and risk factors, 2001: systematic analysis of population health data. Lancet 367, 1747-57.

McCabe, C. 2004: Nurse-patient communication: an exploration of patients' experiences. Journal of Clinical Nursing 13 , 41-49. 
McCormick, R., Adams, P., Powell, A., Bunbury, D., Paton-Simpson, G. and McAvoy, B. 1999: Encouraging general practitioners to take up screening and early intervention for problem use of alcohol: a marketing trial. Drug and Alcohol Review 18, 171-77.

Michie, S., Johnston, M., Francis, J., Hardeman, W. and Eccles, M. 2008: From theory to intervention: mapping theoretically derived behavioural determinants to behaviour change techniques. Applied Psychology 57, 660-80.

Michie, S. and West, R. 2013: Behaviour change theory and evidence: a presentation to government. Health Psychology Review 7, 1-22.

Miller, W.R. 1983: Motivational interviewing with problem drinkers. Behavioural Psychotherapy 11, 147-72.

Miller, W.R. and Rollnick, S. 2009: Ten things that motivational interviewing is not. Behavioural and Cognitive Psychotherapy 37, 129-40.

Ministry of Health. 2007: New Zealand smoking cessation guidelines. Wellington, New Zealand: Ministry of Health.

Ministry of Health. 2008: A portrait of health. Key results of the 2006/07 New Zealand health survey. Wellington: Ministry of Health.

Ministry of Health. 2015: Health targets: more heart and diabetes checks. Retrieved 5 January 2015 from http://www. health.govt.nz/new-zealand-health-system/health-targets/abouthealth-targets/health-targets-more-heart-and-diabetes-checks

Nemec, K. 2001: Review of the Tobacco, Alcohol and Other Drugs Project (TADS). Auckland, New Zealand: Goodfellow Unit, Department of General Practice, University of Auckland.

New Zealand Guidelines Group. 2012: Effective health behaviour change in long-term conditions. A review of New Zealand and international evidence. Wellington: New Zealand Guidelines Group, Ministry of Health.

NHS Information Centre. 2012: Quality and outcomes framework. Retrieved 5 January 2015 from http://www.qof.ic.nhs.uk/

Ogden, J., Bavalia, K., Bull, M., Frankum, S., Goldie, C., Gosslau, M., Jones, A., Kumar, S. and Vasant, K. 2004: 'I Want More Time with My Doctor': a quantitative study of time and the consultation. Family Practice 21, 479-83.

Parsonage, P. 2006: Effective application of the TADS brief interventions for harmful behaviour training programme to PHOs in the Bay of Plenty DHB Evaluation Report. Auckland, New Zealand: Goodfellow Unit, Department of General Practice and Primary Health Care, University of Auckland.

Parsons, M., Senior, H.E., Weidenbohm, K., Parsons, J.G., Jacobs, S.P., Jorgensen, D., Chen, M.-H., Sheridan, N., Kilpatrick, J. and Kenealy, T. 2013: Assessment without action; a randomised evaluation of the interRAI home care compared to a national assessment tool on identification of needs and service provision for older people in New Zealand. Health \& Social Care in the Community 21, 536-44.

Prochaska, J.O. and DiClemente, C.C. 1983: Stages and processes of self-change of smoking: toward an integrative model of change. Journal of Consulting and Clinical Psychology 51, 390-95.
Prochaska, J.O., DiClemente, C.C. and Norcross, J.C. 1992: In search of how people change. Applications to addictive behaviors. American Psychologist 47, 1102-14.

Rea, H., Kenealy, T., Horwood, F., Sheridan, N., Parsons, M., Wemekamp, B., Winter, F., Maingay, G. and Degeling, P. 2010: Integrated systems to improve care for very high intensity users of hospital emergency department and for long-term conditions in the community. New Zealand Medical Journal 123, 76-85.

Roberts, S.E., Goldacre, M.J. and Neil, H.A.W. 2004: Mortality in young people admitted to hospital for diabetes: database study. BMJ 328, 741-42.

Rollnick, S., Kinnersley, P. and Stott, N. 1993: Methods of helping patients with behaviour change. BMJ 307, 188-90.

Rollnick, S. and Miller, W.R. 1995: What is motivational interviewing? Behavioural and Cognitive Psychotherapy 23, 325-34.

Royal New Zealand College of General Practitioners. 2012: Clinical effectiveness model: implementing the ABC alcohol approach in primary care. Wellington, New Zealand: Royal New Zealand College of General Practitioners.

Sammut, J. 2009: Health reform in an ageing Australia: silos or structural reform? Australasian Parliamentary Review 24, 33-49.

Sim, M.G., Wain, T. and Khong, E. 2009: Influencing behaviour change in general practice - Part 1 - brief intervention and motivational interviewing. Australian Family Physician 38, 885-88.

Smith, B.J., Merom, D., Harris, P. and Bauman, A.E. 2002: Do primary care interventions to promote physical activity work? A systematic review of the literature. The New South Wales Centre for Physical Activity and Health Report No. CPAH 03-0002. Melbourne: The National Institute of Clinical Studies; 2002. Retrieved 2003 from http://sydney. edu.au/medicine/public_health/cpah/pdfs/2003_primary_care_ interventions.pdf

Smith, B.J., Tang, K.C. and Nutbeam, D. 2006: WHO health promotion glossary: new terms. Health Promotion International 21, 340-45.

Spoth, R., Greenberg, M. and Turrisi, R. 2008: Preventive interventions addressing underage drinking: state of the evidence and steps toward public health impact. Pediatrics 121 (Suppl 4), S311-36.

TADS Training Programme. 2006: Training of school nurses and public health nurses to assess acceptability and utilisability of the TADS Youth Pact ${ }^{\odot}$ for young people. Performance monitoring return. Auckland, New Zealand: University of Auckland, Department of General Practice and Primary Health Care, Goodfellow Unit.

TADS Training Programme. 2007: Training of school nurses and public health nurses to assess acceptability and utilisability of the TADS Youth Pact ${ }^{\odot}$ for young people. Final Report to Ministry of Health Public Health Directorate and Ministry of Education Waikato. Auckland: Goodfellow Unit, Department of General Practice and Primary Health Care, University of Auckland. 
Vitolins, M.Z., Rand, C.S., Rapp, S.R., Ribisl, P.M. and Sevick, M.A. 2000: Measuring adherence to behavioral and medical interventions. Controlled Clinical Trials 21 (Suppl), S188-94.

Wagner, E.H., Wickizer, T.M., Cheadle, A., Psaty, B.M., Koepsell, T.D., Diehr, P., Curry, S.J., Von Korff, M., Anderman, C., Beery, W.L., Pearson, D.C. and Perrin, E.B. 2000: The Kaiser Family Foundation Community Health Promotion Grants Program: findings from an outcome evaluation. Health Services Research 35, 561-89.

Webster, M.E. 1981: Communication with dying patients. Nursing Times 4, 999-1002.
Welch, G., Rose, G. and Ernst, D. 2006: Motivational interviewing and diabetes: what is it, how is it used, and does it work? Diabetes Spectrum 19, 5-11.

Whitehead, D., Taket, A. and Smith, P. 2003: Action research in health promotion. Education Journal 62, 5-22.

World Health Organization (WHO). 2014: Adolescents: health risks and solutions. Retrieved 10 December 2014 from www. who.int/mediacentre/factsheets/fs345/en/

Wutzke, S.E., Conigrave, K.M., Saunders, J.B. and Hall, W.D. 2002: The long-term effectiveness of brief interventions for unsafe alcohol consumption: a 10-year follow-up. Addiction $97,665-75$. 


\section{Appendix 1: Youth PACT}

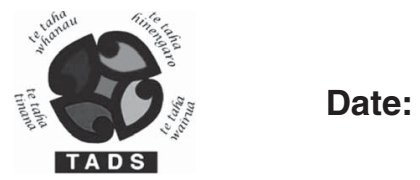

(Author) Youth $\mathrm{PACT}^{\odot}$ (Personal Assessment Choice Tool)

NB: This tool is to be utilised only by those who have accessed the TADS training and have demonstrated competency in the TADS BOI skills alongside implementation of the (Author) Youth PACT॰

Please answer as many questions as you can. Your responses will be confidential to you and will not be read by anyone else.

\section{Do you ever smoke tobacco?}

\begin{tabular}{lr}
$\square$ No & $\square$ Yes \\
\hline Have you ever wanted to cut down or stop smoking toba \\
$\square$ No \\
\\
\hline Do you ever have a drink containing alcohol? \\
$\square$ No \\
\hline Yes
\end{tabular}

Have you ever wished you could cut down on the amount of alcohol you drink ?
$\square$ No
$\square$ Yes
$\square$ Not applicable

Have you ever used party pills or any other drugs such as cannabis?
$\square$ No
$\square$ Yes

Have you ever felt the need to cut down on your drug use?
$\square$ No
$\square$ Yes
Not applicable

Do you enjoy gambling such as lotto, poker, or the internet?

$\square$ No $\quad \square$ Yes

Have you ever wanted to bet more and more money on lotto, card games or the internet?
$\square$ No
$\square$ Yes
Not applicable

If you engage in any sexual activity, does this make you feel OK about yourself?
$\square$ No
$\square$ Yes
Not applicable

(Author) Youth $\mathrm{PACT}^{\oplus}$ 2007. TADS Training Programme. Copyright (Author). Used with permission (Author) 2015 


\begin{tabular}{|c|c|}
\hline \multicolumn{2}{|c|}{ During the past few months, have you felt sad more than you have felt happy? } \\
\hline$\square$ No & $\square$ Yes \\
\hline \multicolumn{2}{|c|}{ Do you sometimes feel it is hard to keep your anger under control? } \\
\hline$\square$ No & $\square$ Yes \\
\hline \multicolumn{2}{|c|}{ Is there one thing in your life right now which is causing you heaps of stress? } \\
\hline$\square$ No & $\square$ Yes \\
\hline \multicolumn{2}{|c|}{ Do you often feel that you are different to your mates and don't fit in? } \\
\hline$\square$ No & $\square$ Yes \\
\hline
\end{tabular}

\section{Do you ever enjoy any form of regular exercise?}
$\square$ No
$\square$ Yes

Do you often feel that it is difficult to control what or how much you eat?

$\square$ No $\quad \square$ Yes

Does your weight sometimes affect the way you feel about yourself?

$\square$ No $\square$ Yes

Thanks for filling out this questionnaire $\mathrm{TADS}^{\odot}$

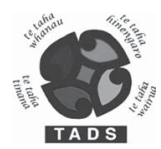

Name or Profile Number:

(Author) Youth PACT $^{\oplus}$ 2007. TADS Training Programme. Copyright (Author). Used with permission (Author) 2015 


\section{Appendix 2: Adult PACT}

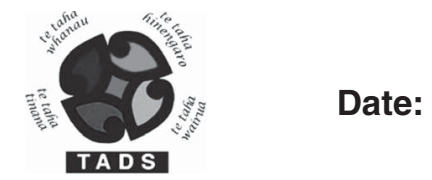

(Author) Adult $\mathrm{PACT}^{\odot}$ (Personal Assessment Choice Tool)

NB: This tool is to be utilised only by those who have accessed the TADS training and have demonstrated competency in the TADS BOI skills alongside implementation of the (Author) Adult PACT $^{\odot}$

Please answer as many of the questions as you can. Your responses will be confidential to you and will not be read by anyone else.

\section{Do you ever smoke tobacco?}

\begin{tabular}{|c|c|c|}
\hline$\square$ No & $\square$ Yes & \\
\hline \multicolumn{3}{|c|}{ Have you ever felt the need to cut down or stop smoking tobacco? } \\
\hline$\square$ No & $\square$ Yes & $\square$ Not applicable \\
\hline \multicolumn{3}{|c|}{ Do you ever have a drink containing alcohol? } \\
\hline$\square$ No & $\square$ Yes & \\
\hline \multicolumn{3}{|c|}{ Have you ever felt the need to cut down on your alcohol intake? } \\
\hline$\square$ No & $\square$ Yes & $\square$ Not applicable \\
\hline \multicolumn{3}{|c|}{ Have you ever used other recreational drugs such as cannabis? } \\
\hline$\square$ No & $\square$ Yes & \\
\hline \multicolumn{3}{|c|}{$\begin{array}{l}\text { Have you ever tried to cut down on your recreational drug use but found this } \\
\text { difficult to do? }\end{array}$} \\
\hline$\square$ No & $\square$ Yes & $\square$ Not applicable \\
\hline \multicolumn{3}{|c|}{ Do you ever engage in any form of gambling (such as the pokies or horses)? } \\
\hline$\square$ No & $\square$ Yes & \\
\hline \multicolumn{3}{|c|}{ Have you ever felt the need to bet more and more money? } \\
\hline$\square$ No & $\square$ Yes & $\square$ Not applicable \\
\hline
\end{tabular}

(Author) Youth $\mathrm{PACT}^{\oplus}$ 2007. TADS Training Programme. Copyright (Author). Used with permission (Author) 2015 


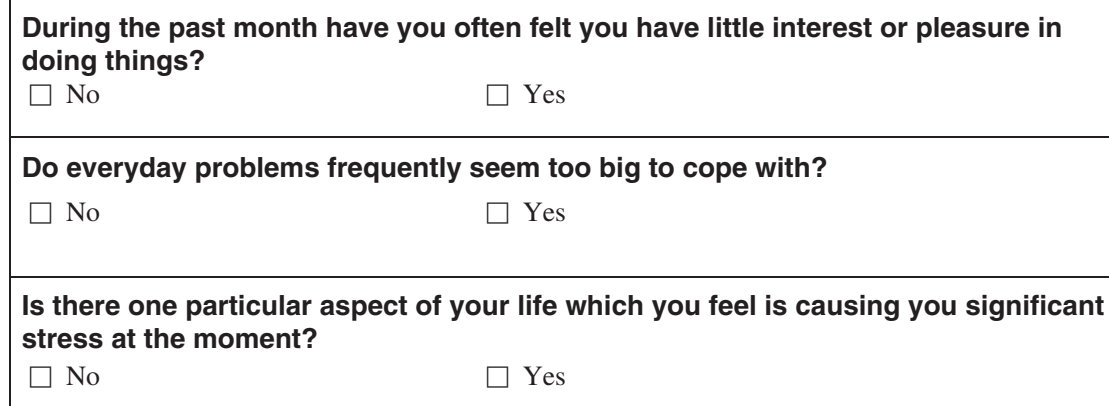

Is there anyone in your life who you are afraid of or who hurts you in any way?

$\square$ No
$\square$ Yes
$\begin{aligned} & \text { Is controlling your anger sometimes a problem for you? } \\ & \square \text { No }\end{aligned}$ Yes

Are you interested in any sort of regular exercise?

$\square$ No $\quad \square$ Yes

Do you often feel that it is difficult to control what or how much you eat?

$\square$ No $\quad \square$ Yes

Does your weight sometimes affect the way you feel about yourself?

$\square$ No $\square$ Yes

Thanks for filling out this questionnaire TADS ${ }^{\odot}$

Name or Profile Number of Respondent:

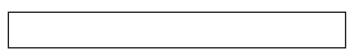

(Author) Youth $\mathrm{PACT}^{\oplus}$ 2007. TADS Training Programmes

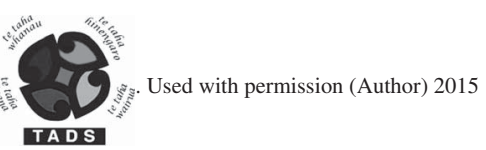

Primary Health Care Research \& Development 2016; 17: 319-332 